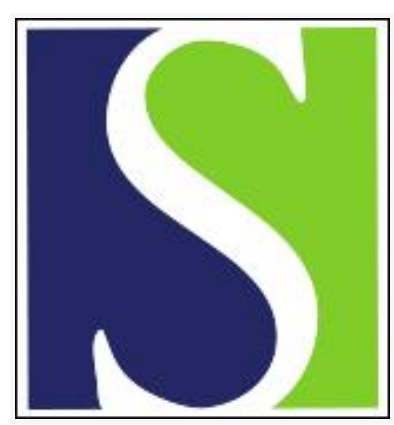

Scand J Work Environ Health 1979;5(2):100-108

https://doi.org/10.5271/sjweh.2663

Issue date: Jun 1979

Ten-year mortality from coronary heart disease among 172,000 men classified by occupational physical activity. by Menotti A, Puddu V

Key terms: coronary heart disease; epidemiology; heart disease; man; mortality; occupational physical activity; physical activity; risk factor

This article in PubMed: www.ncbi.nlm.nih.gov/pubmed/472680

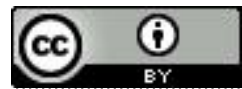




\title{
Ten-year mortality from coronary heart disease among 172,000 men classified by occupational physical activity
}

\author{
by ALESSANDRO MENOTTI, M.D., and VITTORIO PUDDU, M.D.1
}

\begin{abstract}
MENOTTI, A. and PUDDO, V. Ten-year mortality from coronary heart disease among 172,000 men classified by occupational physical activity. Scand. $j$. work environ. \& health 5 (1979) 100-108. A cohort of 172,459 males aged 20-64 years and employed by the Italian railroad system on 1 April 1963 have been classified by habitual physical activity at work and followed-up for death during a ten-year period. The overall crude mortality was 56.59 per 1,000 in ten years, and no significant differences were found between men in sedentary, moderate and heavy work. Age-corrected death rates for coronary heart disease, as manifested by myocardial infarction and sudden coronary death, were substantially different in the three activity groups, moderately active workers ranking first, sedentary workers second, but very close to the former, and very active workers being last. The age-corrected rates for all ages were 14.18, 12.55 and 7.63 per 1,000 in ten years, respectively. All differences were statistically significant, the mortality ratio between the sedentary and moderate groups combined versus the heavy group being of the order of 1.75 to 1 .
\end{abstract}

Key words: coronary heart disease, epidemiology, mortality, physical activity, risk factors.

The role of physical activity as a coronary risk factor has been debated for a long time, and opinions have contrasted due to the difficulties of classifying single individuals as more or less active and to the confounding effects between habitual physical activity and some other risk factors, which, at least in some extensive surveys, could not be measured $(1,2,3,4$, $6,7,8,9,10,11,12,13,14,15,16,17,18$, $19,21,22,24)$.

1 Centre for Cardiovascular Diseases, St. Camillo Hospital, Rome, Italy.

Reprint requests to: Dr. A. Menotti, Laboratory of Epidemiology and Biostatistics, Istituto Superiore di Sanità, Viale Regina Elena 299, 00161 Rome, Italy.
On the other hand gross differences of risk associated with different levels of physical activity can be suggestive - even in the absence of a deeper consideration of other factors - mainly if such results agree with those collected in studies conducted with different methodology.

Some of the recent surveys $(14,16)$ seem to show that only strenuous levels of "habitual" physical activity, exerted for most of one's life, represent a real protective factor against coronary heart disease (CHD). This conclusion is in line with the general agreement of a working group recently convened in Luxembourg by the Commission of the European Communities and the World Health Organization (5).

In 1976 we published a report on the fiveyear mortality from CHD in a large cohort 
of over 172,000 men classified into three categories of occupational physical activity (12). Although such an extensive and crude approach to the problem might not be the best one, our results agreed with the hypothesis that high levels of habitual physical activity at work are protective against fatal CHD. In this current report data on the ten-year follow-up of the same cohort are presented.

\section{MATERIAL AND METHODS}

In 1963 a census was made of all the males employed by the Italian railroad system on 1 April. A total of 172,459 men were classified by age, occupation, type of work, and, mainly, occupational physical activity. The occupational physical activity breakdown was limited, as for the previous reports, to three broad classes, i.e., sedentary (S), moderate $(\mathrm{M})$ and heavy (H) work. This classification was made once, and only at entry, on the basis of a careful analysis of the main types of jobs as directly observed or as described by official manuals of the railroad (table 1). Such limitation was partly overcome by the rather substantial stability of careers in railroad work. The three levels roughly corresponded to a daily energy expenditure of less than 2,400 calories (or 10,045 kJ) (sedentary), 2,4003,000 calories (or 10,045-12,556 kJ) (moderate), and $>3,000$ calories (or $>12,556$ kJ) (heavy).

The cohort was followed-up for ten years, until 31 March 1973, and all cases of death were recorded, including those of the men already in retirement.

The basic information, including causes of death, was collected through the central and peripheral files of the medical service of the railroad, the Board of Pensions, and the register offices of the place where the subjects lived and/or died.

Death causes were coded according to the eighth revision of the international classification of diseases and causes of death (three-digit classification) of the World Health Organization (23). The coder did not know the physical activity class to which the single cases belonged.
Death causes were not necessarily classified as shown on the official certificates. Instead a search was made for the "best" or "most reasonable" cause from all the possible medical information in the health and disease history of each man, as recorded in the personnel files of the railroad. Most of the causes, when death occurred in a hospital, were confirmed by a review of hospital records. Cases indicated as sudden and unexpected (occurring within $24 \mathrm{~h}$ of the onset of symptoms - a detail which could always be checked for men still working) were associated with the code of myocardial infarction when the death was typical for a cardiac mechanism and other possible causes could reasonably be excluded.

The procedure described could be applied in a substantially complete way during the first five years.

The collection of such data during the second five years became more difficult for several reasons, including bureaucratic slowdown and resistance to revealing the cause of death, the large number of subjects retired during the ten-year period (several new regulations between 1967 and 1972 made early retirement easier) and the

Table 1. Main types of jobs requiring different levels of physical activity in the studied population.

\section{Degree of}

physical

activity

Type of job

Sedentary Higher degree of station masters, directors of factories and hangars, higher degree of technicians, secretaries, clerks, telegraphers, interpreters, train conductors, file clerks, doormen, etc.

Moderate Lower degree of station masters, some types of switchmen, locomotive engineers, locomotive and wagon supervisors, factory workers, brakemen, skilled technicians, some types of station general helpers.

Heavy Switchmen, section men, rail maintenance men, unskilled manual workers, some types of locomotive helpers. 
Table 2. Main causes of death in ten years.

\begin{tabular}{|c|c|c|c|}
\hline Causes & $\mathrm{N}$ & $\%$ & \multirow{9}{*}{37.09} \\
\hline $\begin{array}{l}\text { Myocardial infarction and sudden death of probable coronary } \\
\text { origin (ICD codes } 410,411,413 \text { and } 412 \text { when indicated as healed } \\
\text { myocardial infarction, and sudden death as defined in the text) }\end{array}$ & 2,038 & 20.88 & \\
\hline $\begin{array}{l}\text { Other degenerative heart disease (ICD codes } 412 \text {, when not } \\
\text { included in previous point, } 414,400-404,427,428 \text { ) }\end{array}$ & 820 & 8.40 & \\
\hline Strokes (ICD $430-438$ ) & 762 & 7.81 & \\
\hline Cancer, all sites (ICD 140-239) & 2,741 & 28.09 & \\
\hline Violence (ICD E800-E999) & 987 & 10.11 & \\
\hline Liver cirrhosis (ICD 571) & 564 & 5.78 & \\
\hline Chronic bronchitis and similar conditions (ICD 490-493) & 196 & 2.01 & \\
\hline All other causes (ICD all other codes and unknown causes) & 1,651 & 16.92 & \\
\hline All Causes & 9,759 & 100.00 & \\
\hline
\end{tabular}

Table 3. Population at risk classified by age and degree of physical activity at work.

\begin{tabular}{|c|c|c|c|c|c|c|c|c|c|c|}
\hline \multirow{2}{*}{$\begin{array}{l}\text { Degree of } \\
\text { physical } \\
\text { activity }\end{array}$} & \multicolumn{9}{|c|}{ Age group (years) } & \multirow{2}{*}{ Total } \\
\hline & $20-24$ & $25-29$ & $30-34$ & $35-39$ & $40-44$ & $45-49$ & $50-54$ & $55-59$ & $60-64$ & \\
\hline Sedentary & 1,728 & 3,528 & 3,150 & 9,013 & 9,454 & 7,683 & 8,287 & 2,707 & 1,866 & 47,416 \\
\hline Moderate & 656 & 2,660 & 4,346 & 14,821 & 12,984 & 10,866 & 13,242 & 4,228 & 1,090 & 64,893 \\
\hline Heavy & 1,590 & 7,563 & 8,482 & 12,306 & 10,684 & 7,369 & 8,603 & 2,922 & 630 & 60,150 \\
\hline Total & 3,974 & 13,751 & 15,979 & 36,140 & 33,122 & 25,918 & 30,132 & 9,857 & 3,586 & 172,459 \\
\hline
\end{tabular}

consequent increase in the number of men for whom information became more difficult to obtain. Nevertheless it has been estimated that the actual status in life or death was confirmed for more than $95 \%$ of the total cohort, although several deaths of retired men could be classified only as "natural" as shown by the records of the local register offices - in other words only accidents, poisoning and violence could be excluded. This problem accounts for the rather limited type of analysis performed on the ten-year data, as compared to that of the five-year circumstances.

For the final analysis the rates were computed per 1,000 men exposed to risk and the denominators comprised all men originally enrolled in spite of the incompleteness of the information in the numerators.

The age breakdown was limited to quinquennial classes, but, for some compari- sons between levels of occupational physical activity, men in the age group $40-59$ at entry have been considered separately, as a better representative of the problem. Most men belonging to age class $60-64$ were aged $60-62$, and none was aged 65 or more at entry.

Age-corrected rates, when indicated, have been computed by direct standardization separately for "all ages" and "middle-aged men" with the overall railroad population age distribution as the reference population (age-standardized rates).

The significance of differences between the rates of different activity groups were tested with the $z$ ' test between proportions as described by Remington and Schork (20). (See the appendix.)

The particular breakdown of cardiovascular diseases, as shown in table 2, was made with the intention of separating those cases of "degenerative heart disease" 
with a definite or typical coronary involvement from those for which many doubts existed about a true coronary participation in the disease process. There is "myocardial infarction and sudden death of probable coronary origin" (MI + $\mathrm{SD}$ ) on one side and "other degenerative heart disease" on the other, the latter being relatively rare before the age of 60 , at least in terms of mortality.

\section{RESULTS}

\section{Description of the population at risk}

The age and occupation distribution of the men exposed to risk of death is reported in table 3. When this group is compared with any free living population, a shortage of men in the lower and upper age groups is seen. For the older groups and mainly for men engaged in heavy jobs, this difference is due to a documented tendency toward early retirement.

\section{Overall death rates and main causes of death}

A total of 9,759 deaths occurred during the ten years of follow-up, the overall rates per 1,000 being 56.59 . This rate is somewhat lower than that of the Italian male population of the same age and sex. An explanation might be found in the selection of men at the time of employment.

Cardiovascular diseases, when pooled together, cover about $37 \%$ of the total mortality, and they represent the main causes of death. Without such pooling, however, cancer emerges as the single most important cause. The proportion of cases due to myocardial infarction (MI) and sudden death (SD) of possible coronary origin does not differ from that expected from the overall Italian population of the same age and sex. An excess of mortality due to violence as compared to the expected rate is partly explained by some occupational risks.

"All other causes" also includes a num- ber of cases without a precise cause, having been defined as "nautral cause" or simply not having any cause indicated.

\section{Death rates due to all causes}

Death rates per 1,000 in ten years in $\log$ scale for the three activity groups are plotted against age in fig. 1. In spite of some irregularities there is a clear increasing exponential trend and high correlation coefficients.

The regression equations of mortality on age are as follows:

$$
\begin{aligned}
& \text { sedentary men: } \\
& \text { moderately active } \\
& \text { men: } \\
& \begin{array}{l}
y=-0.4006+0.0455 x \\
(r=0.98)
\end{array} \\
& \mathrm{y}=-0.5226+0.0486 \mathrm{x} \\
& (\mathrm{r}=0.97) \\
& y=-0.5454+0.0483 x \\
& (\mathrm{r}=0.95)
\end{aligned}
$$

where $\mathrm{y}=\log$ of mortality and $\mathrm{x}=$ age.

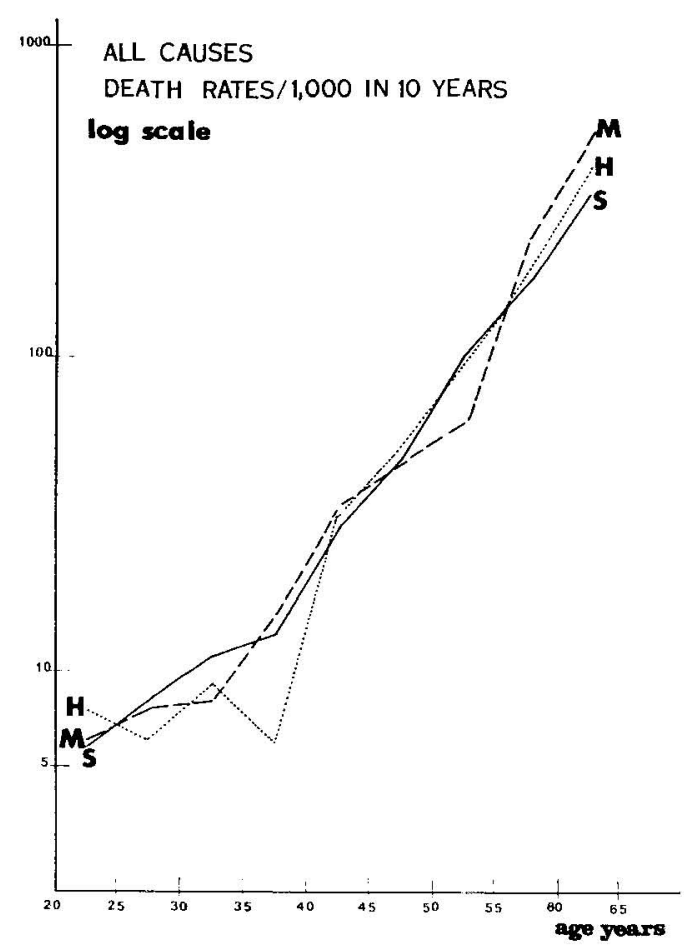

Fig. 1. Death rates for all causes in ten years in three physical activity groups. Rates per 1,000 in $\log$ scale. $(\mathrm{S}=$ sedentary, $\mathrm{M}=$ moderate, $\mathrm{H}=$ heavy work) 
The regression coefficients, although somewhat different in the three activity groups, do not reach statistical differences when compared to each other. The three curves cross each other several times.

Table 4. Death rates due to "all causes." Comparisons between occupational activity groups. Age-corrected rates per 1,000 .

\begin{tabular}{lcc}
\hline $\begin{array}{l}\text { Degree of } \\
\text { physical activity }\end{array}$ & $\begin{array}{c}\text { Age group } \\
40-59 \text { years }\end{array}$ & All ages \\
\hline & & \\
Sedentary (S) & 69.72 & 51.42 \\
Moderate (M) & 65.75 & 52.80 \\
Heavy (H) & 72.36 & 52.50 \\
\hline
\end{tabular}

\begin{tabular}{lcc}
\hline \multicolumn{3}{c}{ p of test $z^{\prime}$ (between proportions) } \\
\hline$S$ vs. $M$ & $<0.05$ & NS \\
$S$ vs. H & NS $^{\mathrm{a}}$ & NS \\
$M$ vs. H & $<0.001$ & NS \\
\hline
\end{tabular}

a NS $=$ not significant.

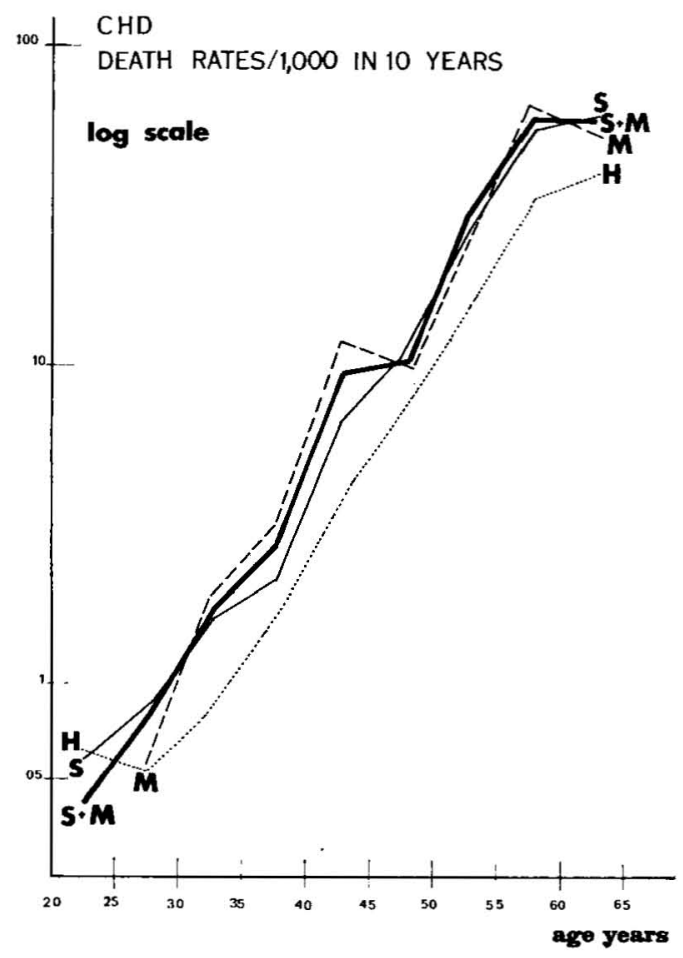

Fig. 2. Death rates for myocardial infarction and sudden death of probable coronary origin in three physical activity groups. Rates per 1,000 in $\log$ scale. ( $\mathrm{S}=$ sedentary, $\mathrm{M}=$ moderate, $\mathrm{H}=$ heavy work)

The overall age corrected death rates are not statistically different in the three groups when all ages are considered. On the other hand a significant excess mortality can be found for men in sedentary versus moderate work and for those in heavy versus moderate work when the middle-aged group is considered (table 4).

Death rates due to myocardial infarction and sudden death of probable coronary origin

Death rates due to myocardial infarction and sudden death of probable coronary origin per 1,000 in $\log$ scale are plotted against age in fig. 2. Also in this figure an increasing trend of the exponential type is clear for all three activity groups. The regression equations of the $\mathrm{MI}+\mathrm{SD}$ rates on age are the following:

sedentary men:

moderately active men:

very active men:

$$
\begin{aligned}
& y=-1.6161+0.0566 x \\
& (x=0.99) \\
& y=-1.7420+0.0600 x \\
& (r=0.98) \\
& y=-1.6748+0.0537 x \\
& (r=0.98)
\end{aligned}
$$

where $\mathrm{y}=\log$ of rates and $\mathrm{x}-$ years.

Neither in this case do the slopes differ significantly. However the curve of the sedentary and moderate groups combined is always clearly separated (except for age group 20-25) from the curve of men in heavy work.

An analytical view of the occupational activity differences related to each single quinquennial age group is reported in table 5 , which considers all the possible comparisons tested with the $z^{\prime}$ statistic. Out of nine comparisons between men in sedentary and moderate work, only one (age group 40-44) indicates significant differences (higher level in moderate group); in nine comparisons between men in sedentary and heavy work five comparisons (all from the age group $40-44$ on) are statistically significant, the rates of sedentary workers being higher than those of men in heavy work; while out of nine comparisons between men in moderate and heavy work four comparisons yield statistically highly significant results (age classes 35$39,40-44,50-54,55-59$ ), with higher rates in the moderate groups. 
Table 5. Comparison between age-occupational activity groups for death rates due to "myocardial infarction and sudden death of probable coronary origin." a

\begin{tabular}{|c|c|c|c|c|c|c|c|c|c|}
\hline & \multicolumn{9}{|c|}{ Age group (years) } \\
\hline & $20-24$ & $25-29$ & $30-34$ & $35-39$ & $40-44$ & $45-49$ & $50-54$ & $55-59$ & $60-64$ \\
\hline $\begin{array}{l}\text { Sedentary } \\
\text { vs. moderate } \\
\text { Sedentary }\end{array}$ & NS & NS & NS & NS & $<0.001$ & NS & NS & NS & NS \\
\hline $\begin{array}{l}\text { vs. heavy } \\
\text { Moderate }\end{array}$ & NS & NS & NS & NS & $<0.01$ & $<0.05$ & $<0.001$ & $<0.001$ & $<0.05$ \\
\hline vs. heavy & NS & NS & NS & $<0.001$ & $<0.001$ & NS & $<0.001$ & $<0.001$ & NS \\
\hline
\end{tabular}

a $p$ of test $z$ ' (between proportion); in significant comparisons $S$ rates are greater than $H$ rates and smaller than $M$ rates; $M$ rates are greater than $S$ and $H$ rates; $H$ rates are smaller than $\mathrm{S}$ and $\mathrm{M}$ rates; $\mathrm{NS}=$ not significant.

The age corrected death rates for MI + $\mathrm{SD}$ are reported in a more synthetic way in table 6. The data show that the moderately active workers rank first in both the "all ages" group and the "middle-aged group," that the very active workers rank last, and that the sedentary workers lie in between but rather clcse to the moderate group. The $z$ ' test of such differences shows significant levels for all comparisons of "all ages"; whereas for "middle-aged men" the sedentary versus moderate group comparison is not significant, but the other two (sedentary vs. heavy and moderate vs. heavy) are highly significant ( $p<0.001$ ).

It clearly appears that, when very large numerators and denominators are involved, also relatively small differences in rates may reach statistically significant levels, but, in this particular case, what becomes especially important is the ratio between different activity groups. For middle-aged men the ratio $\mathrm{S} / \mathrm{M}$ is 0.88 , the ratio $\mathrm{S} / \mathrm{H}$ is 1.67 , and the ratio $\mathrm{M} / \mathrm{H}$ is 1.90. The corresponding ratios for "all ages" are $0.89,1.64$, and 1.86 , respectively. Therefore men in nonheavy work carry with them an excess risk of about $75 \%$ of dieing from MI + SD within ten years. Beyond any other consideration such a difference, if true, seems to yield a definite biological significance.

\section{Comparison of ten versus five years' experience}

The increase of the overall death rate from five to ten years proved to be about
Table 6. Death rates due to "myocardial infarction and sudden death of probable coronary origin." Comparisons between occupational activity groups. Age-corrected rates per 1,000.

\begin{tabular}{|c|c|c|}
\hline $\begin{array}{l}\text { Degree of } \\
\text { physical activity }\end{array}$ & $\begin{array}{l}\text { Age group } \\
40-59 \text { years }\end{array}$ & All ages \\
\hline Sedentary (S) & 18.50 & 12.55 \\
\hline Moderate (M) & 21.08 & 14.18 \\
\hline Heavy $(\mathrm{H})$ & 11.10 & 7.63 \\
\hline \multicolumn{3}{|c|}{$p$ of test $z$ ' (between proportions) } \\
\hline S vs. $M$ & $\mathrm{NS}^{\mathrm{a}}$ & $<0.01$ \\
\hline $\mathrm{S}$ vs. $\mathrm{H}$ & $<0.001$ & $<0.001$ \\
\hline M vs. $\mathbf{H}$ & $<0.001$ & $<0.001$ \\
\hline
\end{tabular}

a $\mathrm{NS}=$ not significant.

1.8 to 1 , perhaps somewhat more than expected.

The differences between the physical activity groups at the five-year follow-up in terms of total mortality (higher mortality in the heavy group in the $40-59$ age range) (12) have remained, but, after ten years, significant differences exist also between the moderate and heavy groups (heavy, higher). No differences were found for the "all ages" corrected rates, however.

In the five-year data on the MI + SD rates (12), only 6 of 27 age-occupation comparisons were statistically significant; while at the ten-year follow-up ten comparisons yielded a p-value of $<0.05$. In the ten-year data the trend of differences followed the same line as that observed in the five-year data, with an excess mor- 
tality among the men in sedentary and moderate work, when compared with the heavy group. More differences also emerge in the ten-year study between the moderate and the sedentary groups, with an excess mortality in the former for several age-occupational activity comparisons and also in the block of "all ages" corrected rates.

\section{COMMENTS}

The presented mortality data seem to answer positively the main question considered by this study. Strenuous physical activity connected with work seems to be a protective factor against early mortality from CHD, as manifested by the most typical clinical patterns (myocardial infarction and sudden coronary death).

The relative risk of nonactive and moderately active men versus very active men is of the order of about 1.7. Such a ratio is in line with those reported by similar studies on large cohorts, like the relative risk of 1.3-1.6 found in a survey of American railroad men (22) and the value of 1.7-1.8 for Californian longshoremen (16). In our group this ratio was substantially similar in the five- and ten-year follow-up (1.65 and 1.7, respectively), a finding suggesting that ageing and the increasing proportion of retirements do not decrease the protection of physical activity against fatal CHD in the form of MI or SD.

The classification of men in terms of physical activity was done only once and was then assumed to be stable. This assumption cannot be completely true, since physical activity at work usually decreases with age and it should drop quite dramatically after retirement.

If the protection predicted by a single early classification of physical activity remains with time, there are at least two possible explanations: (a) heavy physical activity performed for most of one's life also protects after eventual changes like those presumably occurring after retirement, at least for a few years, or (b) men after retirement maintain a sort of phys- ical activity similar to that preceding retirement.

We are also inclined to accept as important the latter hypothesis since it is known that (a) men in heavier jobs are mainly of rural extraction and (b) many, if not all, of them still own a piece of land while engaged in railroad work, and (c) after retirement most of them go back to their original place to take direct care of their land and they continue a sort of rural activity, gardening, etc. Unfortunately a quantitative documentation of this fact is not available.

The exceeding mortality of moderately active men, not only when compared with that of men in heavy work, but also although slightly - when compared with that of sedentary workers, is puzzling. This phenomenon was already apparent from the five-year data. The explanation is unknown. However it is possible that in this particular case some confounding factors, strictly correlated and associated with the fact of being a moderately active worker of the railroad, tend to overwhelm the eventual protective role of moderate physical activity. The amount of such adverse contribution cannot be measured from our data. Still it appears that a lesson for preventive purposes should be elicited from these data, since the depressing fact emerges that a moderate level of occupational physical activity might not be enough for substantial protection against early CHD death if other more powerful factors are operating. A similar conclusion has been recently reported also by Paffenbarger and Hale (16).

The problem of confounding factors can of course be extended to the whole question of the relationship between physical activity and CHD mortality risk. As an example, in this particular group, the parameter "responsibility at work" was considered and analyzed for the first fouryear follow-up. It has been shown that responsibility at work was inversely correlated with physical activity and therefore directly related with CHD mortality.

In this particular group internal differences in salary levels (usually inversely related to physical activity) have never been large and have been reducing year by year; however such differences may be 
associated with differences in dietary, smoking and other living habits.

The ten-year data have confirmed that men in different activity jobs do not differ in overall mortality risk. Whether heavy physical activity per se is responsible for the excess mortality due to causes other than coronary ones cannot be determined from these data although some specific occupational extra-risk was already apparent in the five-year data (violence, chronic bronchitis, etc.) (12).

However the consistency of the hypothesis indicating that habitual physical activity is a protecting factor against CHD tends to be confirmed, if one accepts the fact that a kind of threshold exists and therefore that only heavy muscular activity represents a valid action against early CHD death.

\section{ACKNOWLEDGMENT}

This study was supported by USPHS-NIH grants (Bethesda, Md., U.S.A.) no. OH00162, 5-RO1-U1-00422, 2-RO1-EC-00214, and EDC-5-RO1-OH-00362.

\section{REFERENCES}

1. BRESLOW, L. and BUELL, P. Mortality from coronary heart disease and physical activity work in California. J. chronic dis. 11 (1960) 421-444.

2. BRUNNER, D., MANELIS, G., MODAN, M. and LEVIN, S. Physical activity at work and the incidence of myocardial infarction, angina pectoris and death due to ischaemic heart disease: An epidemiological study in Israeli collective settlements. $J$. chronic dis. 27 (1974) 217-233.

3. CASSEI, J., HEYDEN, S., BARTEL, A. G., KAPLAN, B. H., TYROLER, N. A., CORNONI, J. C. and HAMES, C. G. Occupation, physical activity and coronary heart disease. Arch. intern. med. 128 (1971) 920-928.

4. CHAPMAN, J. M. and MASSEY, F. J. The interrelationship of serum cholesterol, hypertension, body weight and risk of coronary heart disease: Results of the first ten years follow-up in the Los Angeles heart study. J. chronic dis. 17 (1964) 933949.

5. COMMISSION OF THE EUROPEAN COMMUNITIES. Joint EEC/WHO workshop on physical activity in primary prevention of ischaemic heart disease. Luxembourg Feb. 22-24, 1977. Luxembourg 1978, $50 \mathrm{p}$.

6. FOX, S. III and SKINNER, J. S. Physical activity and cardiovascular health. Am. j. cardiol. 14 (1964) 731-746.

7. HICKEY, N., MULCAHY, R., BOURKE, G. J., GRAHAM, I. and WILSON-DAVIS, K. Study of coronary risk factors related to physical activity in 15171 men. $\mathrm{Br}$. med. j. 214 (1975) 507-509.

8. KAHN, H. A. The relationship of reported coronary heart disease mortality to physical activity at work. Am. j. public health 53 (1963) 1058-1067.

9. KANNEL, W. B. and MC NAMARA, P. Physical activity and risk of fatal coronary heart disease: The Framingham study. Circulation 35/36 (1967): suppl. 2, 154-155.

10. KARVONEN, M. J. and BARRY, A. J. (eds.). Physical activity and the heart. Charles C. Thomas, springfield, IL 1967. $405 \mathrm{p}$.

11. KEYS, A. (ed.). Coronary heart disease in seven countries. Circulation 41 (1970): suppl. 1, $211 \mathrm{p}$.

12. MENOTTI, A. and PUDDU, V. Death rates among the Italian railroad employees with special reference to coronary heart disease and physical activity at work. Environ. res. 11 (1976) 331-342.

13. MENOTTI, A., PUDDU, V., MONTI, M. and FIDANZA, F. Habitual physical activity and myocardial infarction. Cardiologia (Basel) 54 (1969) 119-128.

14. MORRIS, J. N., CHAVE, S. P. W., ADAM, C., SIREY, C. and EPSTEIN, L. Vigorous exercise in leisure-time and the incidence of coronary heart disease. Lancet 1 (1973) $333-339$.

15. MORRIS, J. N., KAGAN, A., PATTISON, D. C., GARDNER, M. J. and RAFFLE, P. A. B. Incidence and prediction of ischaemic heart disease in London busmen. Lancet 2 (1966) $553-559$.

16. PAFFENBARGER, R. S. and HALE, W. E. Work activity and coronary heart mortality. N. engl. j. med. 292 (1975) 545-550.

17. PAUL, O., LEPPER, M. H., PHELAN, W. H., DUPERTUIS, G. W., MC MILLAN, A., MC KEAN, H. and PARK, H. A longitudinal study of coronary heart disease. Circulation 28 (1963) 20-31.

18. PELL, S. and D'ALONZO, C. A. A three year study of myocardial infarction in a large employeed population. J. am. med. assoc. 175 (1961) 463-470.

19. PUDDU, V. and MENOTTI, A. An Italian study on epidemiology of ischaemic heart disease. Acta cardiol. 24 (1969) 558-578.

20. REMINGTON, R. D. and SCHORK, M. A. Statistics with applications to the biological and health sciences. Prentice-Hall Inc., Englewood Cliffs, NJ 1970. 418 p.

21. SHAPIRO, S., WEINBLATT, E., FRANK, 
C. W. and SAGER, R. V. The H.I.P. study of incidence and prognosis of coronary heart disease: Preliminary findings on incidence of myocardial infarction and angina. J. chronic dis. 18 (1965) 527-588.

22. TAYLOR, H. L., KLEPETAR, E., KEYS, A., PARLIN, W., BLACKBURN, H. and PUCHNER, T. C. Death rates among physically active and sedentary employees of the rail road industry. Am. $j$. public health 52 (1962) 1967-1976.

23. WORLD HEALTH ORGANIZATION. Man- ual of the international statistical classification of diseases, injuries and causes of death (vol. 1, 8th rev.). World Health Organization, Geneva 1967. 478 p.

24. ZUKEL, W. J., LEWIS, R. H., ENTERLINE, P. E., PAINTER, R. C., RALSTON, L. J., FAWCETTE, R. M., MEREDITH, A. R. and PETERSON, B. A short term community study of the epidemiology of coronary heart disease: A preliminary report of the North Dakota study. Am. $j$. public health 49 (1959) 1630-1639.

Received for publication: 26 October 1978

\section{APPENDIX}

Remington and Schork (20) describe a test on the difference between the parameters of two binomial distributions as follows:

$$
z^{\prime}=-\frac{\hat{p}_{1}-\hat{p},}{\frac{p(1-p)}{n_{1}}+\frac{p(1-p)}{n_{2}}},
$$

where $\hat{p}_{1}$ and $\hat{p}_{2}$ are the proportions in samples 1 and 2 , respectively; $\mathrm{n}_{1}$ and $\mathrm{n}_{2}$ the size of samples 1 and 2 , respectively; and $\mathrm{p}$ is the common value of $\hat{\mathrm{p}}_{1}$ and $\hat{\mathrm{p}}_{\mathrm{s}}$. The hypothesis is $\mathrm{H}$ : $\hat{\mathrm{p}}_{1}-$ $\hat{\mathrm{p}} \cdot \mathbf{2}=0$. The statistic is approximately standard normal if $\mathrm{H}$ is true. A direct and simple connection between $z^{\prime}$ and the chi-square statistics for a $2 \times 2$ contingency table can be demonstrated. 